\title{
Factors affecting regional differences in farmland prices in Finland
}

\author{
Perttu Pyykkönen \\ Pellervon taloudellinen tutkimuslaitos, Eerikinkatu 28,00180 Helsinki,perttu.pyykkonen@ptt.fi
}

\section{Introduction}

Traditionally, farmland prices have varied greatly between different regions in Finland. Joining the European Union in 1995 meant an enormous change in Finnish agricultural policy. The previous support, which mostly consisted of price support, was reduced and area-based support measures were introduced. These support measures do not necessarily take into account differences in land quality; hence, one might expect price differences between good and poor land to have decreased. However, land price differences between regions seem to have increased in recent years.

Taking into account the rapid structural change that is going on in Finnish agriculture, the issues of how and at what price resources, especially land, are transferred to continuing farmers are very important.

The purpose of this study is to determine the factors that affect land prices and how these factors cause regional land price differences. Unlike other land value studies, the interpretation of infrastructure effects here concentrates on the non-farm job opportunities of farm families rather than on the non-farm demand for farmland.

\section{Model}

This study applies firstly a hedonic pricing model. Typical variables used in the estimation of land prices are land characteristics such as quality, parcel size and the length of the growth period. These affect the productivity of land, and thus the expected land rent, but do not reflect the total capability of land to produce income, since agricultural returns are increasingly affected by policy decisions. Thus, support measures are often included in the models (e.g. Goodwin et al. 2002, Barnard et al. 1997).

However, because of the spatial nature of land sales, the effect of local factors may not have been taken into account accurately enough. Thus, spatial econometric analysis that utilizes GIS information included in the data is worth attempting. This analysis will be carried out in the beginning of 2004.

Moreover, agricultural productivity models are inappropriate in capturing all the factors that affect land prices. Another important factor usually included in the models is non-farm demand. Hedonic models have therefore usually been extended by including such factors as distance to the nearest urban area, population density, population growth, housing and recreational values (e.g., Barnard et al. 1997, Boisvert et al. 1997, Roka and Palmqvist 1997, Drescher et al. 2001, Hardie et al. 2001, Nickerson and Lynch 2001, Goodwin et al. 2002).

The dependent variable in the applied model in this study is the sales price of land ( $€ /$ ha). The independent variables and their expected signs are presented in Table 1. Some other explanatory variables (distance to the regional centre, proportion of agricultural land area, buyer's age, proportion of young farmers, proportion of leased land and average farm size) were also modelled in the initial estimations. However, they were excluded from the final model, either due to multicolinearity or their small importance.

The semi-log specification is chosen for the OLS estimation based on a Box-Cox analysis. The sales price is therefore transformed into a logarithmic form, unlike the independent variables.

\section{Data}

The data consists of 2612 arms-length transfers of arable land from 1995 to 1999 recorded by the National Land Survey. In addition to the sales price, the data includes information about the parcel size, location and whether a lake, river or sea borders the parcel. This price data was extended by incorporating municipality level data from different sources. The descriptive statistics of the variables are summarised in Table 1. 


\section{Results}

The estimation results of the hedonic analysis are presented in Table 2. The negative coefficient of parcel size confirms the common result of lower transaction costs for larger parcel sizes. The dummy variable (DWATER) indicates that the irrigation possibility (or some recreational value) increases the land price by nearly $10 \%$ at mean level.

The six variables controlling the productivity effects (yield, length of thermic growth period and the four support variables) are all positive and significant. The elasticities of support measures (calculated at the mean value level) are quite low compared to the yield elasticity (Table 3). However, when roughly estimating the effect of a $€ 1$ increase in support or in market returns (based on the value of the yield), the income sources seem to have a similar effect on the land price. The discount rates were around 0.10 .

The next set of variables (farm density, manure density, and part-time level) controls the agricultural structure. Farm density is significantly positive, indicating that the greater the number of potential buyers for the specific parcel, the higher the price. The positive and significant sign for manure density reflects structural change and the increased demand for additional land due to environmental pressure. The effect of the part-time variable is negative, as expected, but not significant.

The fourth variable set consists of infrastructure variables. They are all significant and of the expected sign. The less important agriculture is in a region, the higher the land prices seem to be. This variable is also correlated with the part-time variable in the previous set, which may explain the nonsignificance of the parttime variable. Population density and such variables as distance to the nearest city, urbanization level and housing value are usually included in land value models to indicate the urban pressure and the non-farm demand for land. Nevertheless, as Finland is a large and generally sparsely populated country, the urban pressure as such may not be a very relevant factor. What is more, the proportion of agricultural land is indeed very small compared to other EU countries. Hence, the non-farm demand for farmland for future development cannot be very large. However, the population density together with the unemployment factor works as a proxy for the job opportunities and availability of services in the neighbouring area. This is a very relevant factor considering the part-time nature of Finnish family farms, since less than half of their net income is derived from agriculture. The better the non-farm job opportunities are, the more reliably the farm family can regard the future of their agricultural production. Hence, the willingness to pay more for the additional land is greater.

Due to the rising trend in prices, most of the year-dummies have a positive sign. However, with the exception of 1999, the coefficients are not significant. This means that the other variables have already captured the trend.

\section{Conclusions}

In this analysis, the importance of agricultural productivity measures was high. As expected, the area-based support as well as the land quality measures positively affected land prices. Moreover, land prices appeared to react similarly to different income sources. This probably reflects the unique nature of Finnish agricultural conditions. Even the tremendous support that is needed to enable farming to continue does not seem to be capitalized into the land prices any more than market returns.

The infrastructure also had a very important role in determining the price level of agricultural land. If other industries are prospering in the surrounding area, agricultural viability also seems to improve. The nonfarm opportunities offered to farm families make continuing and developing farming more tempting. This is mainly due to the part-time nature of Finnish agriculture, even though the coefficient of this particular factor is not significant.

Since the estimation results of this preliminary hedonic model seem to be very relevant, the model is well suited to utilisation in the spatial econometric approach that will be adopted in a future project. The spatial analysis is based on the distances between different sales. Whether the spatial dependence affects land prices can be studied by two model specifications that have a slightly different interpretation. If the spatial lag specification is the correct one the result can be interpreted so that during the trade negotiations the partners (buyer and seller) take into account the prices paid in other sales in the neighbourhood. If the spatial error specification is the correct one the result can be interpreted so that there are some local factors that cannot be measured but that affect the price level in the area.

Another important enlargement of the model will be to gather information for more recent years, since the policy changed again in 2000. Preliminary analysis for the year 2000 indicated that further research is needed. 


\section{References}

Barnard, C. H., Whittaker, G., Westenbarger, D. \& Ahearn, M. 1997. Evidence of Capitalization of Direct Government Payments into U.S. Cropland Values. Amer. J. Agric. Econ. 79, 642-1650.

Boisvert, R. N., Schmit, T. M. \& Regmi, A. 1997. Spatial, Productivity, and Environmental Determinants of Farmland Values. Amer. J. Agric. Econ. 79, 1657-1664.

Drescher, K., Henderson, J. \& McNamara, K. 2001. Farmland Price Determinants. Paper presented at AAEA Annual Meeting in Chicago 2001.

Goodwin, B. K., Mishra, A. K. \& Ortalo-Magné, F. N. 2002. Differentiated Policy Impacts on Agricultural Land Values. Paper presented at USDA Conference on Government Policy and Farmland Markets: Implications of the New Economy. Washington May 2002.

Hardie, I. W., Narayan, T. A. \& Gardner, B. L. 2001. The Joint Influence of Agricultural and Nonfarm Factors on Real Estate Values: An Application to the Mid-Atlantic Region. Amer. J. Agric. Econ. 83, 120-132.

Nickerson, C. J. \& Lynch, L. 2001. The Effect of Farmland Preservation Programs on Farmland Prices. Amer. J. Agric. Econ. 83, 341-351.

Roka, F. M. \& Palmqvist, R. B. 1997. Examining the Use of National Databases in a Hedonic Analysis of Regional Farmland Values. Amer. J. Agric. Econ. 79, 1651-1656.

Table 1. Descriptive statistics of the variables, and the expected signs of the explanatory variables in the estimation.

\begin{tabular}{|lllll|}
\hline Variable & Variable name & Mean & Std.Dev. Exp. sign \\
\hline PRICE & Sales price, $€$ /ha & 3450 & 2117 & \\
\hline PSIZE & Parcel size, ha & 6.28 & 5.92 & - \\
\hline DWATER & Dummy=1 if parcel bordered by lake, river, or sea & 0.07 & 0.26 & + \\
\hline AVYIELD & Average yield in the region (barley kg/ha) & 3289 & 206 & + \\
\hline THERMICG & Length of the thermic growth period (days) & 160 & 8.78 & + \\
\hline CAP & Area based CAP support $(€ /$ ha) & 111 & 47 & + \\
\hline LFA & LFA support $(€ /$ ha) & 144 & 53 & + \\
\hline ENV & Environmental support $(€ /$ ha) & 102 & 31 & + \\
\hline OTHER & Other area based support $(€ /$ ha) & 45 & 17 & + \\
\hline FARMDEN & Farm density $($ Number of farms/km2) & 0.71 & 0.36 & + \\
\hline MANDEN & Manure density $($ Pkg/ha) & 5.69 & 2.39 & + \\
\hline PARTTIME & Proportion of agricultural income in farm households $(\%)$ & 0.39 & 0.09 & - \\
\hline AGRLAB & Proportion of agricultural labour from total labour $(\%)$ & 0.19 & 0.10 & - \\
\hline POPDENS & Population density (inhab./km2) & 20.66 & 39.07 & + \\
\hline UNEMPL & Unemployment rate $(\%)$ & 0.14 & 0.05 & - \\
\hline D96 & Year-dummies & 0.14 & 0.35 & + \\
\hline D97 & & 0.15 & 0.35 & + \\
\hline D98 & & 0.21 & 0.41 & + \\
\hline D99 & & 0.20 & 0.40 & + \\
\hline
\end{tabular}


Table 2. Regression results of the estimated semi-log model. The dependent variable is the logarithm of the sales price.

\begin{tabular}{|c|c|c|c|}
\hline & Coefficient & $\mathrm{t}$-value & signif. \\
\hline Intercept & 3.92400 & 9.96 & $* * *$ \\
\hline PSIZE & -0.00923 & -5.38 & $* * *$ \\
\hline DWATER & 0.08687 & 2.47 & * \\
\hline AVYIELD & 0.00031 & 4.22 & $* * *$ \\
\hline THERMICG & 0.01255 & 5.97 & $* * *$ \\
\hline CAP & 0.00302 & 4.55 & $* * *$ \\
\hline LFA & 0.00317 & 4.55 & $* * *$ \\
\hline ENV & 0.00246 & 2.42 & * \\
\hline OTHER & 0.00264 & 2.91 & $* *$ \\
\hline FARMDEN & 0.40635 & 9.79 & $* * *$ \\
\hline MANDEN & 0.02406 & 4.14 & $* * *$ \\
\hline PARTTIME & -0.35182 & -2.38 & $*$ \\
\hline AGRLAB & -0.27887 & -2.34 & $*$ \\
\hline POPDENS & 0.00120 & 4.81 & $* * *$ \\
\hline UNEMPL & -2.33601 & -7.72 & $* * *$ \\
\hline D96 & 0.06657 & 1.81 & $\mathrm{o}$ \\
\hline D97 & 0.00097 & 0.03 & \\
\hline D98 & 0.01022 & 0.29 & \\
\hline D99 & 0.09427 & 2.46 & $*$ \\
\hline \multicolumn{4}{|c|}{ Adjusted $\mathrm{R}^{2}=0.391$} \\
\hline \multicolumn{4}{|c|}{$\mathrm{F}(18,2592)=94.081 ; \mathrm{p}<0.0000$} \\
\hline
\end{tabular}

Table 3. Elasticities of yield and support variables with respect to sales price (calculated at the mean value level).

\begin{tabular}{|ll|}
\hline & Elasticity \\
AVYIELD & 1.020 \\
CAP & 0.314 \\
LFA & 0.427 \\
ENV & 0.244 \\
OTHER & 0.116 \\
\hline
\end{tabular}

